\title{
Transformation and Strategic Development of Human Resource Management in Public Sector Under Digital Economy
}

\author{
Liu Xitao ${ }^{1,2}$, Xu Yongyang ${ }^{1 *}$ \\ ${ }^{1}$ School of Finance and Public Administration, Harbin University of Commerce, Harbin, Heilongjiang150028, China \\ ${ }^{2}$ School of Finance and Public Administration, Harbin University of Commerce, Harbin, Heilongjiang150028, China \\ *Corresponding author. Email: 1415630272@qq.com
}

\begin{abstract}
The vigorous development of digital economy brings opportunities as well as challenges to various countries. It is inevitable for the government public departments to take the initiative to adapt to the wave of digital economy. President Xi Jinping fully emphasized the importance of talents for the development of the country at the Fifth Plenary Session of the nineteenth Central Committee of the state. Therefore, human resources management in public sector should adapt to the transformation of digital economy as soon as possible. This paper believes that fully understanding digital talents is the basis of promoting the transformation of traditional human resource management in public sector, and promoting the combination of management tools and emerging technologies such as data, artificial intelligence and blockchain in the digital economy is the guarantee of transformation and development. This paper puts forward some suggestions on the transformation and strategic development of public sector human resource management system under the digital economy, and puts forward its own ideas for exploring the establishment of public sector human resource management system in line with national development.
\end{abstract}

Keywords: Digital economy, human resource, management digital talents

\section{DIGITAL TRANSFOEMATION, ENTERING A NEW DIGITAL ECONOMY}

The era of digital economy is an era of comprehensive application of Internet, Internet of things, cloud computing, big data and artificial intelligence. [1] It is an era of highly awakening of talents' self-consciousness and innovation skills, and an era of co evolution and integration of human needs and technology. For the public sector, the realization of digital transformation and the improvement of digital viability are not only the response to national development policies, but also the inevitable choice not to be eliminated by science and technology.

\subsection{The Coming of Digital Economy Era}

Since 2011, the United States has successively issued federal cloud computing strategy, big data research and development plan and other strategies. Germany has fully implemented the industry 4.0 strategy, and released digital strategy (2015-2018) and other documents in 2016. [2] The development of China's digital economy has also entered a fast track. According to the calculation of the China Institute of information and communications, the scale of China's digital economy reached 27.2 trillion yuan in 2017, accounting for $32.9 \%$ of GDP. [2] At the nineteenth plenary session of the Fifth Central Committee, President Xi Jinping also proposed that we should speed up the development of digitalization, develop the digital economy, strengthen the construction of digital society and digital government, and enhance the level of digitalization and intellectualization of public services and social governance. To promote the deep integration of digital technology and real economy, the era of digital economy has come.

\subsection{The Foundation of Digital Economy Transformation}

The essence of digital transformation is the transformation of human activities driven by technology, and the reorganization of human economic and social 
life is the essential problem faced by digital transformation. At the level of public sector, human resource management transformation is an important part of digital transformation strategy of public sector.

In the traditional human resource planning, the commonly used methods include trend analysis, ratio analysis, regression analysis and expert prediction. With the help of big data technology, talents can be screened and managed through data analysis and big data integration.

\section{DIGITAL TALENTS, A NEW PATH OF HUMAN RESOURCE MANAGEMENT TRANSFORMISION}

\subsection{The Change of Talents' self-consciousness In The Era of Data Economy}

By 2020, most of the post-90s, who grew up in the era of rapid development of science and technology and information explosion, have entered the society. This generation has more innovation, but also more self-awareness, more ideas in work autonomy, and more needs for self-respect and personal value realization. These requirements are not only reflected in the working methods and contents, but also the requirements for the working environment and working mode.

In the development of human resource management, the positioning of "human" can be divided into four stages. [4] In the first stage, "man" is a tool. In the early industrial and agricultural society, the first elements of production were land and capital. In the second stage, "people" and "post" match. As a "tool", different individuals will bring different outputs under the same production conditions, and the concept of human resource management has gradually emerged and developed. In the third stage, "human" and "matter" interaction. With the deepening of the understanding of human resources, the value of human resources has been found more and more. In the fourth stage, "man" is the purpose. With the advent of the digital economy era, human capital has become the first factor of production. This idea was put forward by the philosopher Kant and quickly accepted by the public. Human resource management has entered a new stage. Therefore, the understanding of digital talents is the first step in the transformation of human resource management in public sector.

\subsection{Probabilistic Automata}

By 2020, most of the post-90s, who grew up in the era of rapid development of science and technology and information explosion, have entered the society. This generation has more innovation, but also more self-awareness, more ideas in work autonomy, and more needs for self-respect and personal value realization.
These requirements are not only reflected in the working methods and contents, but also the requirements for the working environment and working mode.

In the development of human resource management, the positioning of "human" can be divided into four stages. In the first stage, "man" is a tool. In the early industrial and agricultural society, the first elements of production were land and capital. In the second stage, "people" and "post" match. As a "tool", different individuals will bring different outputs under the same production conditions, and the concept of human resource management has gradually emerged and developed. In the third stage, "human" and "matter" interaction. With the deepening of the understanding of human resources, the value of human resources has been found more and more. In the fourth stage, "man" is the purpose. With the advent of the digital economy era, human capital has become the first factor of production. This idea was put forward by the philosopher Kant and quickly accepted by the public. Human resource management has entered a new stage. [5]Therefore, the understanding of digital talents is the first step in the transformation of human resource management in public sector.

\section{NEW MANAGEMENT LAYOUT, ACCELERATE THE TRANSFORMATION OF MANAGEMENT TOOLS}

\subsection{Building a New Human Resource Management System}

New situation, new ideas, to build a complete new human resource management system, we need to do the following. The first is to optimize the working environment, update office equipment and assist the reform of human resource management. [2] According to the trend of digital technology change and the objective situation of local public sector, we should adjust flexibly. It is necessary to clarify the core competence of human resources, strengthen various personnel systems, and ultimately optimize the internal environment and atmosphere of the public sector. The second is to effectively implement the people-oriented management principle and clarify the management concept of serving the people. Whether people have enthusiasm and how much enthusiasm they have in their work is very important for their office ability and efficiency. Therefore, it is necessary to clarify the system and improve the efficiency. The public sector has many methods in human resource management assessment, among which 360 degree assessment method has been widely used because of its rich perspectives and high degree of fit with blockchain technology. [3] The third is to scientifically standardize the system and allocate human resources. Under certain cost constraints, it is necessary to realize the optimal 
allocation of human resources in the public sector, realize the efficient coordination of labor elements, economic elements and technical elements, and avoid structural contradictions in the allocation of human resources.

\subsection{Innovating the means of human resource management}

The object of human resource management is human. Compared with other modules, human resource management is less controllable, more difficult and more professional. [5] Therefore, the use of data analysis, artificial intelligence and other technologies to improve the level of human resource management has become an urgent task. The application of data analysis, artificial intelligence and other technologies can improve the predictability of human resource management and achieve forward-looking management. However, it is necessary to pay special attention to the humanization problems existing in the artificial intelligence technology citation. Humanization is a very important concept of modern human resource management. Human resource management based on data and artificial intelligence are all procedural management. For example, in the performance appraisal, a staff member's performance can be adjusted by a gap of 0.01 . The public sector should pay special attention to the use of data analysis and artificial intelligence in human resource management. [1]

\section{THE DEVELOPMENT STRATEGY OF HUMAN RESOURCE MANAGEMENT IN PUBLIC SECTOR UNDER DAT ECONOMY}

The traditional functional human resource management model has been unable to adapt to the requirements of the digital era, so I describe the development strategy of public sector human resource management in the digital era from three aspects of "selection, use and education". [5]

(1) In terms of personnel selection. The goal of public sector talent selection is no longer to match the work content, but to recruit new and comprehensive talents, create an open human resource ecological environment, and ensure that the public sector can quickly respond to changes in the external environment.

(2) In terms of employment. The main performance of "human resources" and "human resources" in the evaluation of work. In the digital era, "evaluation" no longer takes value creation as the only standard. Department employees pursue more self-worth and self creation, and their needs become diversified. The salary system of public sector should also change from single to multiple. The single salary incentive mode should be transformed into comprehensive recognition and encouragement, including recognition of work tasks and service Cooperation recognition, benchmarking behavior recognition, citizen behavior recognition, growth recognition, etc. Create a good working atmosphere by fully recognizing the incentive mode. Staff should cooperate with each other to concentrate superior resources and promote the continuous improvement of the public sector.

(3) Education. Position based human resource management ensures the high efficiency of work through the matching of human resource and position. In the digital era, human resources are no longer attached to the organization, but according to the Department Reform and environmental changes, cultivate compound talents. It is necessary not only to transform the public resources, but also to develop the human resources.

\section{CONCLUSION}

The arrival of digital economy era promotes the reform and development of human resource management in public sector. This paper takes "digital talents" as the basic point, and expounds the importance of talents for the reform of human resources management in public sectors in detail. Digitalization is not only a technological change, but also a cognitive change, a new understanding of talents and technology.

In the era of digital economy, "talent" is the most important resource. When recruiting new talents, the public sector should have a basic understanding and understanding of data-based talents. When introducing big data and artificial intelligence for management, we should not ignore the humanization. We should also consider the needs and ideas of "talents" when building a new talent management system. In the future strategic development, we should put "people" in the first place, and make strategic formulation from the three aspects of personnel selection, employment and education. Based on human beings, we should focus on talents, and finally create a public sector human resource management system in line with national development.

\section{REFERENCES}

[1] Hang Siqiao, Human resource reform brought by digital economy, Business News.06(2019)190-191.

[2] Zhang Xiuyu, Human resource management transformation in the digital economy era, Knowledge economy. 19(2019)104-105.DOI: https://doi.org/10.15880/j.cnki.zsjj.2019.19.063

[3] Yang Yunfeng, Analysis of human resource management in the public sector, modern business. 14(2020)62-63.DOI: https://doi.org/10.14097/j.cnki.5392/2020.14.028 
[4] Tian Shenghai, Digital revolution of human resources, Internet economy. 06 (2018)84-89.DOI: https://doi.org/10.19609/j.cnki.cn10-1255/f.2018.0 6.018

[5] He Haifeng, Zhang Jiantong, Liu Yuanxing, Talents and employment in the digital economy era, new economy guide. 11 (2018)76-82. 